\title{
PENGGUNAAN MEDIA INTERAKTIF POWER POINT DALAM PEMBELAJARAN DARING
}

\author{
${ }^{1}$ B. Fitri Rahmawati, ${ }^{2}$ Badarudin, ${ }^{3}$ Muhammad Shulhan Hadi \\ $1,2,3$ Universitas Hamzanwadi \\ ${ }^{1}$ fitri.fkiphamzanwadi@gmail.com
}

\begin{abstract}
Abstrak
Merebaknya pandemi Covid 19 mengubah model pembelajaran tatap muka menjadi pembelajaran daring. Pembelajaran daring lebih banyak dilakukan secara tidak langsung (asynchronous) sehingga membutuhkan media pembelajaran yang dapat mendukung penyampaian materi dari guru kepada siswa. Salah satu media yang dapat digunakan adalah media interaktif power point. Penelitian ini bertujuan untuk mengetahui keefektifan penggunaan media interaktif power point terhadap hasil belajar sejarah. Metode yang digunakan adalah pre eksperimen dengan model one shot case study dimana tidak ada kelas kontrol dan tidak ada pretes. Keefektifan terlihat dari rerata skor hasil belajar yang diperoleh siswa dibandingkan dengan skor KKM yang telah ditetapkan (75). Uji analisis menggunakan rumus one sample t-test. Hasil penelitian menunjukkan nilai sig. (2-tailed) = $0,001<0,05=\alpha$ yang berarti penggunaan media interaktif power point efektif terhadap hasil belajar sejarah siswa di MAN 1 Lombok Timur. Berdasarkan hasil tersebut maka dapat direkomendasikan untuk menggunakan media interaktif power point sebagai alternatif media pembelajaran daring.
\end{abstract}

\section{Kata Kunci: efektivitas, interaktif media power point, hasil belajar}

\begin{abstract}
The outbreak of the Covid 19 pandemy changed the face-to-face learning model into online learning. Online learning is more predominantly carried out indirectly (asynchronously) requiring learning media that can support the delivery of material from teachers to students. One of the media that can be used is interactive power point media. This study aims to determine the effectiveness of using interactive power point media on learning outcomes of history. The method used was preexperiment with one shot case study model where there was no control class and no pretest. The effectiveness can be seen from the mean score of learning outcomes obtained by students compared to the predetermined KKM score (75). The analysis test used the one sample t-test formula. The results showed the sig. $(2$-tailed $)=0.001<0.05=\alpha$, which means that the use of interactive power point media is effective on student history learning outcomes at MAN 1 East Lombok. Based on these results, it can be recommended to use interactive power point media as an alternative to online learning media.
\end{abstract}

Keyword: effectiveness, interactive power point media, learning outcome

\section{PENDAHULUAN}

Merebaknya covid 19 di Indonesia memberikan dampak pada semua lini kehidupan, tanpa terkecuali pada bidang pendidikan, khususnya kegiatan pembelajaran. Beberapa dampak yang ditimbulkan diantaranya 1) sekolah dialihkan ke rumah melalui proses pembelajaran daring; 2) terjadi transformasi media pembelajaran berbasis teknologi melalui penggunaan Wathshap Group, Zoom, Google Classroom, WebEx, Youtube, dan saluran TV (TVRI) penyesuaian metode 
Penggunaan Media Interaktif ..... B. Fitri Rahmawati, Badarudin, Muhammad Shulhan Hadi

pembelajaran; 3) penyesuaian evaluasi pembelajaran untuk penentuan standar kenaikan kelas dan kelulusan; dan 4) tuntutan kolaborasi orangtua peserta didik di rumah sebagai pengganti guru mengontrol pembelajaran anak (Mansyur, 2020), 5) Peningkatan penggunaan teknologi dalam pembelajaran; dan 6) Peningkatan kemandirian belajar mahasiswa (Firman, 2020).

Dampak tersebut cukup mengejutkan semua pihak karena tidak tidak sesuai dengan apa yang sudah direncanakan sebelumnya yakni kegiatan tatap muka. Semua stakeholder di sekolah dipaksa untuk dapat menerima kondisi dan dalam waktu yang bersamaan harus dapat menyiapkan strategi yang tepat untuk dapat efektifnya pembelajaran. Banyak persoalan yang kemudian menjadi bahan diskusi berbagai pihak. Bagaimana caranya pembelajaran yang awalnya tatap muka diubah menjadi pembelajaran yang dilakukan di rumah agar tujuan pembelajaran dapat tercapai, dengan kondisi peserta didik yang berasal dari latar belakang yang berbeda, tempat tinggal yang berbeda dan fasilitas yang berbeda pula.

Pembelajaran online pun menjadi salah satu pilihan yang paling banyak dipilih dimana pembelajaran dilakukan secara daring dengan perantara jaringan internet. Sebagaimana yang dinyatakan Hanum pembelajaran online atau e-learning adalah salah satu bentuk model pembelajaran melalui dunia maya yang difasilitasi dan didukung pemanfaatan teknologi informasi dan komunikasi (Hanum, 2013). Oleh karena itu, penguasaan teknologi menjadi penting bagi guru. Bagaimana pun juga, keberadaan fasilitas jika tidak didukung oleh kemampuan dalam menggunakannya, tidak akan dimanfaatkan dengan baik. Realitas menunjukkan bahwa kompetensi guru-guru di Indonesia masih rendah dalam dunia Teknologi Informasi dan Komunikasi (Engko \& Usmany, 2020; Purwanto et al., 2020; Setyorini, 2020). Hal tersebut menjadi salah satu kendala, mengingat bahwa pembelajaran daring dilakukan melalui perangkat teknologi, sehingga membutuhkan kompetensi guru dalam mengoperasikannya.

Dari faktor siswa juga menemui hambatan dalam pembelajaran daring. Peserta didik merasa jenuh dan bosan selama melaksanakan pembelajaran (Putria et al., 2020). Banyak peserta didik mengeluhkan banyaknya tugas yang diberikan oleh guru. Jika di analisis, kesan ini terjadi karena siswa belum memahami dan menerima perubahan tentang model pembelajarannya. Normalnya, jika materi dibelajarkan di dalam kelas, maka siswa cukup membaca ataupun kegiatan eksplorasi materi lainnya kemudian mendiskusikannya secara langsung bersama guru dan teman-temannya. Akan tetapi dalam pembelajaran daring, kegiatan ini tidak dapat dilakukan sehingga untuk menyampaikan apa yang sudah dipahami oleh siswa dapat ditunjukkan lewat tulisan yang dalam hal ini dipahami sebagai tugas. Kondisi ini juga menyebabkan penguasaan materi pelajaran menjadi berkurang (Rahmawati, 2020). Pembelajaran asynchronous misalnya, guru hanya memberikan materi dalam bentuk perintah membaca atau dengan membuatkan handout dan menjelaskannya secara singkat 
Penggunaan Media Interaktif ..... B. Fitri Rahmawati, Badarudin, Muhammad Shulhan Hadi

lewat pesan di WhatsApp ataupun Google Classroom, membuat banyak siswa tidak memahami materi dengan baik. Meskipun ada diskusi tetapi tidak seefektif dalam diskusi tatap muka.

Selain itu, pembelajaran daring juga menyebabkan komunikasi dan sosialisasi antar siswa menjadi menurun (Setyorini, 2020). Kegiatan belajar yang dilakukan dari rumah masing-masing dan kebijakan social distancing melarang siswa untuk bertemu dengan teman-temannya. Jika pada pembelajaran normal, siswa dapat berinteraksi dengan teman-temannya, bermain bersama dan belajar bersama, maka tidak demikian dalam pembelajaran daring. Siswa hanya dapat berinteraksi lewat dunia maya.

Seperti yang disampaikan sebelumnya, bahwa salah satu kendala yang dihadapi siswa adalah pemahaman terhadap materi pelajaran. Peserta didik merasa kesulitan dalam memahami materi pelajaran karena tidak disampaikan secara langsung dalam kegiatan pembelajaran tatap muka. Ketika tatap muka, informasi mengenai materi yang disampaikan guru dapat didengar secara langsung dan terjadi interaksi timbal balik secara langsung antara guru dan peserta didik, sehingga ketika terdapat materi yang belum dipahami, dapat ditanyakan langsung dan direspon langsung baik oleh guru maupun sesama peserta didik. Hal ini menjadi tantangan bagi guru tentang bagaimana mengemas materi pembelajaran agar peserta didik dapat belajar secara mandiri dan mampu memahaminya dengan baik. Salah satu hal yang masih menjadi kendala dari guru sejarah di MAN 1 Lombok Timur adalah mengenai media pembelajaran yang dapat digunakan dalam pembelajaran daring.

Media pembelajaran adalah alat untuk menyampaikan pesan berupa materi kepada peserta didik. Media pembelajaran yang tepat dapat membantu peserta didik dalam mencapai tujuan pembelajaran yakni hasil belajar yang tinggi. Oleh karena itu, guru harus mampu memilih dan mendesain media pembelajaran yang tepat (Nurseto, 2011). Salah satu media yang dapat digunakan dalam pembelajaran daring adalah media pembelajaran interaktif dalam bentuk power point. Media pembelajaran interaktif efektif dalam meningkatkan penguasaan konsep (Novita \& Harahap, 2020) dan mampu meningkatkan antusiasme siswa (Putri \& Sibuea, 2014) karena tanggapan siswa terhadap media power point interaktif sangat baik (Warkintin \& Mulyadi, 2019). Oleh karena itulah, peneliti mencoba menyusun media pembelajaran interaktif untuk dilihat efektivitasnya dalam pembelajaran daring di MAN 1 Lombok Timur. Media pembelajaran yang dibuat adalah media pembelajaran dalam bentuk power point yang interaktif.

Power Point yang digunakan adalah pola Stand Alone. Menurut Daryanto, pola Stand Alone adalah pola penyajian Microsoft Office Powerpoint yang dirancang khusus untuk pembelajaran individual yang bersifat interaktif (Sugiyono, 2016). Powerpoint Stand Alonen merupakan salah satu media yang digunakan untuk mempersentasekan atau menjelaskan sesuatu yang dirangkum dan dikemas ke dalam beberapa slide yang menarik (Nasution, 2020). 


\section{METODE PENELITIAN}

Metode penelitian yang digunakan dalam penelitian ini adalah metode pre eskperimen. Menurut Sugiono (2016: 73) menyatakan bahwa pre-experimental merupakan belum eksperimen sungguh-sungguh yang masih terdapat variabel luar yang ikut berpengaruh, desain ini tidak adanya variabel kontrol. Jenis pre-experimental design yang digunakan dalam penelitian ini adalah one shot case study, dimana penelitian ini tidak ada kondisi awal atau adanya perlakuan awal karena melibatkan sekelompok subjek atau diberi satu perlakuan (X) dan dites akhir (O). Berikut desain penelitian one shot case study yang menurut Sugiono (2016: 109).

\section{XO}

Gambar 1. Desain Penelitian One Shot Case Study XO

Keterangan:

$\mathrm{X}=$ Treatment yang diberikan (variabel independen)

$\mathrm{O}=$ Observasi (variabel dependen)

Kelas yang digunakan sebagai tempat penelitian ini adalah kelas XI IPS 1 dengan jumlah siswa sebanyak 31 orang. Penelitian ini dilakukan dengan tujuan untuk mengetahui efektivitas penggunaan media pembelajaran dalam pembelajaran daring. Efektifitas dalam penelitian ini ditentukan dengan melihat rerata skor hasil belajar sejarah siswa apabila lebih dari 75 . Uji analisis data menggunakan uji one sample t-test dengan terlebih dahulu diuji prasyarat berupa uji normalitas data menggunakan uji Kolmogorov-Smirnov. Proses analisis menggunakan bantuan software SPSS. Uji one sample t test digunakan untuk mengetahui apakah rerata skor hasil belajar sejarah siswa lebih tinggi dari nilai KKM yakni 75 yang menandakan efektivitas penggunaan media interaktif power point.

\section{Hasil Penelitian}

Berdasarkan hasil analisis terhadap hasil belajar siswa setelah menggunakan media power point interaktif adalah diperoleh mean sebesar 80,81 (dibulatkan) dan standar deviasi sebesar 8,86 (dibulatkan) dan digambarkan pada tabel berikut ini:

Tabel 1. Rata-Rata Hasil Belajar Sejarah Siswa

\begin{tabular}{lcccc}
\hline & N & Mean & Std. Deviation & Std. Error of Mean \\
\hline Hasil Belajar Sejarah & 31 & 80.8065 & 8.85972 & 1.59125 \\
\hline
\end{tabular}

Hasil uji normalitas data menggunakan uji Kolmogorov-Smirnov Z diperoleh nilai signifikansi sebesar 0,432 yang lebih besar dari 0,05 (Sig. > 0,05) sehingga distribusi skor hasil 
Penggunaan Media Interaktif ..... B. Fitri Rahmawati, Badarudin, Muhammad Shulhan Hadi

belajara yang diperoleh siswa dinyatakan normal. Hasil uji coba dapat disajikan pada tabel berikut ini:

Tabel 2. Hasil Uji Normalitas Data

\begin{tabular}{lccccc}
\hline & $\mathbf{N}$ & Mean & $\begin{array}{c}\text { Std. } \\
\text { Deviation }\end{array}$ & $\begin{array}{c}\text { Kolmogorov } \\
\text {-Smirnov Z }\end{array}$ & $\begin{array}{c}\text { Asymp. Sig. } \\
\text { (2-tailed) }\end{array}$ \\
\hline Hasil Belajar Sejarah & 31 & 80.8065 & 8.85972 & 0.873 & 0.432 \\
\hline
\end{tabular}

Penelitian ini bertujuan untuk melihat efektivitas penggunaan media interaktif power point terhadap hasil belajar sejarah siswa. Dikarenakan tidak ada kelas yang menjadi kelas kontrol, maka efektivitas dilihat dari perbandingan nilai rerata hasil belajar sejarah siswa dengan KKM untuk mata pelajaran sejarah yakni sebesar 75. Selanjutnya akan diuji menggunakan one sample t test dengan berbantukan Software SPSS. Pengujian ini dilakukan untuk melihat apakah rerata skor hasil belajar sejarah siswa lebih tinggi daripada nilai KKM yakni sebesar 75 yang menandakan efektivitas penggunaan media interaktif power point.

Adapun hasil pengujian menggunakan one sample $t$ test dapat digambarkan pada tabel berikut ini:

Tabel 3. Hasil Uji Hipotesis

\begin{tabular}{lllll}
\hline & \multicolumn{4}{l}{ Test Value $=75$} \\
\cline { 2 - 5 } & $\mathrm{t}$ & Df & Sig. (2-tailed) & Mean Difference \\
\hline Hasil belajar Sejarah & 3.649 & 30 & .001 & 5.80645 \\
\hline
\end{tabular}

Berdasarkan Tabel 3 tersebut di atas, diperoleh nilai sig. (2-tailed) $=0,001<0,05=\alpha$, yang berarti bahwa rerata skor hasil belajar sejarah siswa setelah menggunakan media power point interaktif lebih besar dari 75. Hal tersebut menjelaskan bahwa penggunaan media power point interaktif efektif terhadap hasil belajar sejarah siswa di MAN 1 Lombok Timur.

\section{HASIL DAN PEMBAHASAN}

Dalam pembelajaran daring, ruang kelas diganti dengan kelas virtual. Guru dan siswa melakukan interaksi melalui perangkat mobile dengan bantuan jaringan internet. Berbagai media dapat digunakan untuk mendukung pelaksanaan pembelajaran secara online (Firman \& Rahayu, 2020). Berbagai layanan kelas virtual dapat dimanfaatkan misalnya Edmodo (Enriquez, 2014), Schoology (Sicat \& Ed, 2015), dan Google Classroom (Iftakhar, 2016) serta sosial media berupa WhatsApp maupun facebook. Melalui pembelajaran daring, interaksi dapat dilakukan secara langsung (synchronous) maupun tidak langsung (asynchronous). Pembelajaran langsung (synchronous) misalnya dapat dilakukan melalui Zoom dan Google Meet. Sedangkan pembelajaran 
Penggunaan Media Interaktif ..... B. Fitri Rahmawati, Badarudin, Muhammad Shulhan Hadi

asynchronous dapat dilakukan melalui WhatsApp, atau melalui LMS berupa e-learning, Google Classroom, Etmodo, Schoology dan lain sebagainya. Untuk dapat memanfaatkan semua aplikasiaplikasi pembelajaran tersebut, guru harus memiliki kompetensi di bidang Teknologi Komunikasi dan Informasi agar pembelajaran dapat berjalan efektif.

Dalam proses pembelajaran di MAN 1 Lombok Timur, guru menggunakan e-learning, zoom dan media sosial whatsApp. WhatsApp dan Zoom digunakan untuk diskusi, sedangkan e-learning digunakan untuk memberikan tugas dan evaluasi. Proses pembelajaran ini berlangsung sebanyak 3 kali pertemuan untuk pembahasan materi pembelajaran dan 1 kali pertemuan untuk evaluasi. Setiap pertemuan pembelajaran berlangsung selama 35 menit. Pada proses pembelajaran siswa diharuskan untuk mengisi absen kehadiran, di pengsisian absensi yang ada pada fitur yang disediakan pada elearning tersebut dan kemudian guru memberikan rentang waktu untuk memberikan siswa untuk mempersiapkan diri untuk keseriusan dan konsentrasi siswa dalam menerima instruksi yang diberikan.

Guru menyediakan materi melalui powerpoint pada setiap pertemuan melalui aplikasi zoom atau WhatsApp dan memberikan waktu kepada siswa untuk memahami materi tersebut. Setelah itu, guru membuka forum diskusi terkait dengan materi yang sedang dibahas. Semua siswa diminta untuk berpartisipasi dalam kegiatan diskusi, baik dalam memberikan pertanyaan maupun dalam menjawab pertanyaan. Guru mengamati jalannya diskusi dan sesekali memberikan klarifikasi jika terdapat kekeliruan pemahaman dari siswa dan menjadi penengah ketika terjadi perdebatan. Setiap akhir pembelajaran, guru bersama siswa menyimpulkan materi. Setelah materi yang terdapat pada power point selesai dibahas, siswa kemudian diberikan soal evaluasi untuk melihat hasil belajar siswa.

Analisis hasil evaluasi menunjukkaan bahwa rata-rata hasil belajar sejarah siswa setelah diterapkan pembelajaran menggunakan media pembelajaran sebesar 80,81 . Hasil ini menunjukkan skor yang lebih besar dari KKM yang sudah ditetapkan yaitu sebesar 75. Hasil pengujian dengan menggunakan rumus one sample t-test diperoleh nilai sig. (2-tailed) $=0,001<0,05=\alpha$, yang menunjukkan bahwa pembelajaran menggunakan media interaktif power point tergolong efektif dalam pembelajaran daring pada mata pelajaran sejarah.

Hasil penelitian ini sejalan dengan penelitian Mardian dan Akbar, yang menunjukkan bahwa jenis media pembelajaran yang digunakan memiliki pengaruh terhadap hasil belajar ataupun dalam hal proses pembelajaran yang dilakukan (Mardhiah \& Akbar, 2018). Penggunaan media power point misalnya dapat mempengaruhi minat siswa dalam belajar (Susanti et al., 2020) meningkatkan konstentrasi dalam mengikuti proses pembelajaran sehingga penggunaan media pembelajaran Power Point efektif digunakan dalam proses pembelajaran (Misbahudin et al., 2018). Sedangkan media pembelajaran interaktif, efektif untuk meningkatkan penguasaan konsep (Novita \& Harahap, 
Penggunaan Media Interaktif ..... B. Fitri Rahmawati, Badarudin, Muhammad Shulhan Hadi

2020) serta mampu meningkatkan antusiasme siswa (Putri \& Sibuea, 2014). Dalam penelitian dan pengembangan media, tanggapan siswa terhadap media power point interaktif sangat baik (Warkintin \& Mulyadi, 2019).

\section{KESIMPULAN}

Pemanfaatan media pembelajaran sangat penting untuk mendukung penyampaian materi. Salah satu media pembelajaran yang dapat digunakan adalah media power point interaktif. Hasil penelitian menunjukkan bahwa media power point interaktif efektif terhadap hasil belajar sejarah siswa. Hal ini ditunjukkan dengan perolehan rereta nilai siswa di atas KKM. Hasil pengujian melalui one sample t-test juga menunjukkan bukti efektivitas penggunaan media power point interaktif ini. Oleh karena itu dapat diberikan saran untuk dijadikan sebagai salah satu alternatif media dalam pembelajaran daring.

\section{DAFTAR PUSTAKA}

Engko, C., \& Usmany, P. (2020). Dampak Pandemi Covid-19 Terhadap Proses Pembelajaran Online. Jurnal Akuntansi, 6(1), 23-38.

Enriquez, M. A. S. (2014). Students' Perceptions on the Effectiveness of the Use of Edmodo as a Supplementary Tool for Learning. DLSU Research Congress, 1-6.

Firman, F. (2020). Dampak Covid-19 terhadap Pembelajaran di Perguruan Tinggi. BIOMA: Jurnal Biologi Dan Pembelajarannya, 2(1), 14-20.

Firman, F., \& Rahayu, S. (2020). Pembelajaran online di tengah pandemi covid-19. Indonesian Journal of Educational Science (IJES), 2(2), 81-89.

Hanum, N. S. (2013). Keefetifan e-learning sebagai media pembelajaran (studi evaluasi model pembelajaran e-learning SMK Telkom Sandhy Putra Purwokerto). Jurnal Pendidikan Vokasi, $3(1)$.

Iftakhar, S. (2016). Google classroom: what works and how? Journal of Education and Social Sciences, 3(1), 12-18.

Mansyur, A. R. (2020). Dampak covid-19 terhadap dinamika pembelajaran di indonesia. Education and Learning Journal, 1(2), 113-123.

Mardhiah, A., \& Akbar, S. A. (2018). Efektivitas media pembelajaran terhadap hasil belajar kimia siswa SMA Negeri 16 Banda Aceh. Lantanida Journal, 6(1), 49-58.

Misbahudin, D., Rochman, C., Nasrudin, D., \& Solihati, I. (2018). Penggunaan Power Point Sebagai Media Pembelajaran: Efektifkah? WaPFi (Wahana Pendidikan Fisika), 3(1), 43-48.

Nasution, K. (2020). Pengemasan Materi Pembelajaran Tari Wira Pertiwi Berbasis Powerpoint Stand Alone Untuk Sekolah Menengah Atas. Gesture: Jurnal Seni Tari, 9(2), 185-194. 
Penggunaan Media Interaktif ..... B. Fitri Rahmawati, Badarudin, Muhammad Shulhan Hadi

Novita, R., \& Harahap, S. Z. (2020). Pengembangan media pembelajaran interaktif pada mata pelajaran sistem komputer di SMK. Informatika, 8(1), 36-44.

Nurseto, T. (2011). Membuat media pembelajaran yang menarik. Jurnal Ekonomi Dan Pendidikan, $8(1)$.

Purwanto, A., Pramono, R., Asbari, M., Hyun, C. C., Wijayanti, L. M., \& Putri, R. S. (2020). Studi Eksploratif Dampak Pandemi COVID-19 Terhadap Proses Pembelajaran Online di Sekolah Dasar. EduPsyCouns: Journal of Education, Psychology and Counseling, 2(1), 1-12.

Putri, I. P., \& Sibuea, A. M. (2014). Pengembangan media pembelajaran interaktif pada mata pelajaran fisika. Jurnal Teknologi Informasi \& Komunikasi Dalam Pendidikan, 1(2), 145-155.

Putria, H., Maula, L. H., \& Uswatun, D. A. (2020). Analisis proses pembelajaran dalam jaringan (daring) masa pandemi covid-19 pada guru sekolah dasar. Jurnal Basicedu, 4(4), 861-870.

Rahmawati, B. F. (2020). Learning By Google Classroom in Students' Perception. Journal of Physics: Conference Series, 1539(1), 12048.

Setyorini, I. (2020). Pandemi COVID-19 Dan Online Learning: Apakah Berpengaruh Terhadap Proses Pembelajaran Pada Kurikulum 13? Journal of Industrial Engineering \& Management Research, 1(1), 95-102.

Sicat, A. S., \& Ed, M. A. (2015). Enhancing college students' proficiency in business writing via schoology. International Journal of Education and Research, 3(1), 159-178.

Sugiyono, S. (2016). Metode Penelitian Kuantitatif, Kualitatif dan R \& D. In Bandung: Alfabeta.

Susanti, E., Ritonga, M., \& Bambang, B. (2020). Pengaruh Penggunaan Media Powerpoint Terhadap Minat Belajar Bahasa Arab Siswa. Arabiyatuna: Jurnal Bahasa Arab, 4(1), 179192.

Warkintin, W., \& Mulyadi, Y. B. (2019). Pengembangan Bahan Ajar Berbasis CD Interaktif Power Point Untuk Meningkatkan Hasil Belajar Siswa. Scholaria: Jurnal Pendidikan Dan Kebudayaan, 9(1), 82-92. 